\title{
The prevalence and risk assessment of aflatoxin in sesame-based products
}

\author{
Ali Heshmati ${ }^{1}$, Mina Khorshidi ${ }^{1 *}$, Amin Mousavi Khaneghah ${ }^{2 *}$ \\ ${ }^{1}$ Department of Nutrition and Food Safety, School of Medicine, Nutrition Health Research Center, Hamadan University of \\ Medical Sciences, Hamadan, Iran; ${ }^{2}$ Department of Food Science and Nutrition, Faculty of Food Engineering, University of \\ Campinas (UNICAMP), São Paulo, Brazil
}

"Corresponding Author: Mina Khorshidi, Department of Nutrition and Food Safety, School of Medicine, Nutrition Health Research Center, Hamadan University of Medical Sciences, Hamadan, Iran. Email: mkhorshidi2992@gmail.com; Mousavi Khaneghah, Department of Food Science and Nutrition, Faculty of Food Engineering, University of Campinas (UNICAMP), São Paulo, Brazil. Email: mousavi@unicamp.br

Received: 9 May 2021; Accepted: 4 June 2021; Published: 5 July 2021

(c) 2021 Codon Publications

OPEN ACCESS C(1) (1)(2)

PAPER

\begin{abstract}
The contamination of aflatoxins (AFs) in 120 samples of sesame seeds, tahini, and tahini halva collected from Iran's market were evaluated. The exposed risk due to ingestion of aflatoxin $\mathrm{B}_{1}\left(\mathrm{AFB}_{1}\right)$ via their consumption was estimated with the aid of the Monte Carlo simulation (MCS). The highest prevalence of AF (55\%) was associated with sesame seed samples, followed by tahini (45\%) and tahini halva (32.5\%). The AFB concentration in sesame seeds, tahini, and tahini halva was in the ranges of $0.21-12.35,0.23-5.81$, and $0.27-3.56 \mu \mathrm{g} / \mathrm{kg}$, respectively. The concentration of the total aflatoxin (TAF) in $7(17.5 \%), 8(20 \%)$, and $2(5 \%)$ samples of sesame seeds, tahini, and tahini halva, respectively, was below the limit of European regulations $(4 \mu \mathrm{g} / \mathrm{kg})$, while the levels of $\mathrm{AFB}_{1}$ in 10 (25\%), 7 (17.5\%), and 6 (15\%) samples of sesame seeds, tahini, and tahini halva, respectively, were higher than the European regulations $\left(2 \mu \mathrm{g} / \mathrm{kg}\right.$ ). As the percentile 50 and 95 of margin of exposure (MOE) with $\mathrm{AFB}_{1}$ for sesame seed, tahini, and tahini halva was more than 10,000, it could conclude the intake of aflatoxin through the consumption of mentioned products did pose a not remarkable cancer risk for adults.
\end{abstract}

Keywords: mycotoxin; contamination; risk assessment; traditional products; sesame based

\section{Introduction}

Today, humans pay considerable attention to food safety and contaminants (Milicevic et al., 2021; Rapa et al., 2021; Xinyu et al., 2020). Mycotoxins produced by fungi are among the most important food contaminants and have a negative impact on public health, food safety, and the national economy of many countries, especially developing countries (Batrinou et al., 2020; Grumi et al., 2020). The most critical factors in food contamination with mycotoxins are moisture, intrinsic properties and nutrients, long shelf life and $\mathrm{pH}$, and high-water activity (Wang et al., 2018). Aflatoxins (AFs) are produced by Aspergillus fungi, especially A. flavus and $A$. parasitics and rarely by $A$. nomius (De Souza et al., 2021; Heshmati et al., 2019). They pose carcinogenic, mutagenic, immunosuppressive, and teratogenic consequences. The most common AFs are aflatoxin $\mathrm{B}_{1}$ $\left(\mathrm{AFB}_{1}\right), \mathrm{B}_{2}\left(\mathrm{AFB}_{2}\right), \mathrm{G}_{1}\left(\mathrm{AFG}_{1}\right)$, and $\mathrm{G}_{2}\left(\mathrm{AFG}_{2}\right)($ Heshmati et al., 2017). $\mathrm{AFB}_{1}$ is the most carcinogenic type for humans and animals (Mokhtarian et al., 2020). The International Agency for Research on Cancer (IARC) classified $\mathrm{AFB}_{1}$ as a group 1 carcinogen (Elzupir et al., 2010).

Aflatoxins production may occur during harvesting, transportation, storage, or on the farm. AFs are very stable chemical compounds resistant to heat and food processes (Cui et al., 2020). They can contaminate various foods, including cereal, dairy products, oilseeds, 
spices, and nuts (Javanmardi et al., 2020; Khaneghah et al., 2018; Mozaffari Nejad et al., 2020).

Due to the high toxicity of AFs, exposure to these contaminations could threaten human health. The Committee on Food Additives of Joint FAO/WHO (JECFA) recommends that the presence of mycotoxins in meals be minimized to reduce the potential risk (Di Sanzo et al., 2018). Therefore, in order to control AFs in food products, some regulations were established in many countries; the measurement and monitoring of AFs in food products are crucial (Sebaei et al., 2020).

With the scientific name of Sesamum indicum L., sesame seed belongs to the Pedaliaceae family and is one of the oldest and most momentous oilseeds globally (Lee et al., 2020). It contains $58 \%-44 \%$ oil, $25 \%-25 \%$ protein, $13.5 \%$ carbohydrates, and 5\% ash (Kollia et al., 2016). It is also a significant source of dietary fiber and micronutrients such as minerals, including calcium, phosphate, iron, potassium, vitamins such as E, thiamine, and niacin, lignans tocopherols, and phytosterols (Elleuch et al., 2011; Yao et al., 2021). Sesame seeds have antioxidant, anti-inflammatory, anti-fungal, anti-viral, and natural antibacterial effects (Dravie et al., 2020). Sesame seeds are consumed in different forms in the world (Namiki, 2007). It is widely used in the Iranian food industry as an ingredient in confectionery products, bread, and pastries. Therefore, ensuring the mycotoxicological quality of sesame is very important (Asadi et al., 2011; EghbaljooGharehgheshlaghi et al., 2020; Elleuch et al., 2011; Kollia et al., 2016).

Tahini is made by grinding and roasting sesame seeds known in the Middle East (Gholami et al., 2020; Sebaei et al., 2020). Tahini halva, also known as halva, helva, halawi, halawh, is produced by mixing tahini with sugar, citric or tartaric acid, and Saponaria officinalis root extract (Öğütcü et al., 2017; Osaili et al., 2018a; Var et al., 2007). Consumption of tahini halva has increased due to its excellent nutritional value and health properties in other countries, including the United States and European countries, Iran, Turkey, Saudi Arabia, Iraq, Greece, Jordan, Bulgaria, and Bosnia and Herzegovina (Anilakumar et al., 2010). Tahini halva consists of about $45 \%$ tahini, $45 \%-55 \%$ sugar, $2 \%$ ash, and $2.5 \%$ moisture and is consumed with bread in breakfast and dinner (Osaili et al., 2018b).

When sesame seeds were stored improperly, they can be contaminated with mycotoxins, especially AFs (Anthony et al., 2014). Therefore, the EU sets limits for $\mathrm{AFB}_{1}$ and TAF in sesame and its products as 2 and $4 \mu \mathrm{g} / \mathrm{kg}$, respectively. In contrast, the limit of these mycotoxins, according to the Iranian Institute of Standards and Industrial Research (ISIRI), was 5 and $15 \mu \mathrm{g} / \mathrm{kg}$ (INSO, 2020). The prevalence of AFs in sesame seeds and their products was demonstrated by previous studies (Anthony et al., 2014; Apeh et al., 2016; Asadi et al., 2011; Esan et al., 2020; Fapohunda et al., 2018; Hosseininia et al., 2014; Kollia et al., 2016; Li et al., 2009; Reddy et al., 2011; Sabry et al., 2016; Sebaei et al., 2020; Sirhan et al., 2014; Tabata, 2007; Torlak and Akan, 2013; Var et al., 2007).

No studies have been performed to evaluate mycotoxin contamination in tahini and tahini halva samples available in Iran's market. Therefore, the current study aimed to determine the level of AFs in sesame seed, tahini, and tahini halva, and halva consumed in western Iran. Furthermore, the exposed risk due to ingestion of $\mathrm{AFB}_{1}$ via their consumption was estimated with the aid of the Monte Carlo simulation (MCS).

\section{Material and Methods}

\section{Materials}

Acetonitrile, $\mathrm{HNO}_{3}(65 \%)$, phosphate buffer solution (PBS), methanol, Potassium bromide ( $\mathrm{KBr})$, were purchased from Merck (Darmstadt, Germany). The AF standards were purchased from Sigma-Aldrich (St. Louis, MO, USA)

\section{Sample collection}

Samples $(n=120 ; 40$ fresh sesame seed, 40 tahini, and 40 tahini halva) were collected from the local market in Hamadan province, Iran, from April 2020 until August 2020. Samples were stored in a refrigerator $\left(4^{\circ} \mathrm{C}\right)$ until analysis.

\section{Chemical properties}

Moisture content (\%) of sesame seed, tahini, and tahini halva was determined by drying in an oven at $100^{\circ} \mathrm{C}$. The protein and fat contents of samples were determined by the Kjeldahl method and Soxhlet extraction, respectively (Zebib et al., 2015). Extracted fat acidity was measured by titration by sodium hydroxide $\left(0.01^{\circ} \mathrm{N}\right)$ in the presence of phenolphthalein as an indicator.

\section{Extract and cleanup of AF}

The method applied for the extraction and cleanup of AF was similar to the previous one with slight modifications (Torlak and Akan, 2013). Samples were wholly powdered and mixed. Fifty grams of ground sample was weighed and transferred into a $250 \mathrm{~mL}$ flask. Then, $150 \mathrm{~mL}$ of a mixture of water and methanol $(30: 70 ; \mathrm{v} / \mathrm{v})$ was added and placed 
on a shaker and stirred for $10 \mathrm{~min}$. Then, it was filtered through filter paper of Whatman No. 2. Twenty milliliters of filtered solutions were collected and transferred into a $100 \mathrm{~mL}$ flask, and $40 \mathrm{~mL}$ of distilled water was added and mixed for 5 min and filtered. For the cleanup of AFs, 15 $\mathrm{mL}$ of filtrate was transferred through the immunoaffinity column at a flow rate of 2-3 drops/s. Further, the column was washed three times with $10 \mathrm{~mL}$ distilled water at the same flow rate. The elution of AFs was performed by acetonitrile $(1 \mathrm{~mL})$. The eluate was gathered in a vial, and its volume was reached $2 \mathrm{~mL}$ with acetonitrile. Then, $100 \mu \mathrm{L}$ of eluted AFs was injected into a high-performance liquid chromatography (HPLC) instrument.

\section{Analysis of AFs}

The quantification of AFs in sesame products was carried out by HPLC (Knauer-Germany), equipped with a Smartline Pump, fluorescence detector, reverse phased C18 (150 $\mathrm{mm} \times 4.6 \mathrm{~mm}$ i.d and $5 \mu \mathrm{m}$ particle size). In the fluorescence detector, an excitation wavelength of $333 \mathrm{~nm}$ and emission wavelength of $430 \mathrm{~nm}$ was applied for AFs determination. The mobile phase was water/methanol/ acetonitrile $(6: 102: 94, \mathrm{v} / \mathrm{v} / \mathrm{v})$ and contained $100 \mathrm{mg} \mathrm{KBr}$ and $100 \mu \mathrm{L} \mathrm{HNO}_{3}$. Then, it is diverted into HPLC in the isocratic method with a flow rate of $0.8 \mathrm{~mL} / \mathrm{min}$. The column temperature of HPLC was maintained at $40^{\circ} \mathrm{C}$.

\section{The validation of AFs analysis method}

The linearity, accuracy, repeatability, limit of detection (LOD), and limit of quantification (LOQ) were determined (Heshmati et al., 2017).

\section{Risk assessment}

For risk assessment of $\mathrm{AFB}_{1}$ intake through sesames seed, tahini, and tahini halva, the probabilistic approach was considered and estimated daily intake (EDI). The following equations are used to calculate the margin of exposure (MOE):

EDI $(\mathrm{ng} / \mathrm{kg}$ bw/day $)=$ the concentration of AFB $\times$ average daily consumption $(\mathrm{kg}) /$ average body weight $(\mathrm{kg})$

Per capita consumption of sesame in Iran is $3 \mathrm{~g} /$ day (Eghbaljoo-Gharehgheshlaghi et al., 2020). In this study, $70 \mathrm{~kg}$ is considered as the mean body weight for an adult in Iran.

MOE = benchmark dose lower confidence limit 10\% $\left(\mathrm{BMDL}_{10}\right) / \mathrm{EDI}$ where, $\mathrm{BMDL}_{10}$ is the lowest dose that is $95 \%$ certain to cause no more than $10 \%$ cancer prevalence. The EFSA Panel on Contaminants in the Food Chain (CONTAM) suggested $400 \mathrm{ng} / \mathrm{kg} \mathrm{BW} /$ day for $\mathrm{BMDL}_{10}$ reference value (Chain et al., 2020). A MOE of 10,000 or larger has little concern for public health, while a MOE of less than 10,000 shows a potential danger for consumers (Heshmati et al., 2017). EDI and MOE were estimated by MCS using Crystal ball software (version 11.1.2.3 Oracle).

\section{Statistical analysis}

For statistical analysis, the SPSS software version 20 (IBM, PASW Statistics, USA) was applied. The mean and standard deviation of AFs levels in different samples were determined. One sample T-test was used to compare the mean of $\mathrm{AFB}_{1}$ and TAF with the allowable limit. The significant level was considered $P<0.05$. One-way ANOVA and Tukey's test were applied to determine the significant difference of moisture, fat, protein content, and extracted fat acidity levels of these samples.

\section{Result and Discussion}

\section{The chemical properties of samples}

The moisture, fat, protein, and extracted fat acidity amount of sesame seed, tahini, and tahini halva samples are shown in Table 1. Sesame seed had a higher moisture, fat, and protein value than tahini and tahini halva samples.

\section{Method validation}

The LOD of AFs for sesame seeds, tahini, and tahini Halva samples ranged from 0.04 to $0.08,0.05$ to 0.09 , and 0.07 to $0.08 \mu \mathrm{g} / \mathrm{kg}$, respectively while LOQ for them ranged from 0.13 to $0.25,0.18$ to 0.31 , and 0.21 to $0.27 \mu \mathrm{g} / \mathrm{kg}$, respectively (Table 2). Moreover, the recovery range for AFs of sesame seeds, tahini, and tahini halva samples was 82.15-96.23, 77.36-95.63, and 83.65-98.65, respectively (Table 3). The determination coefficients $\left(R^{2}>0.992\right)$ of the

Table 1. Chemical proprieties of sesame and related products.

\begin{tabular}{lrrr} 
Parameters & Sesame seed & Tahini & Tahini halva \\
\hline Moisture (\%) & $6.87 \pm 0.38^{\mathrm{a}}$ & $1.15 \pm 0.07^{\mathrm{c}}$ & $2.5 \pm 0.06^{\mathrm{b}}$ \\
Fat (\%) & $52.31 \pm 2.89^{\mathrm{a}}$ & $49.13 \pm 2.12^{\mathrm{b}}$ & $28.45 \pm 2.32^{\mathrm{c}}$ \\
Protein (\%) & $22.34 \pm 1.87^{\mathrm{a}}$ & $20.67 \pm 1.76^{\mathrm{b}}$ & $9.87 \pm 0.75^{\mathrm{c}}$ \\
$\begin{array}{l}\text { Extracted fat } \\
\text { acidity (\%, in }\end{array}$ & $0.82 \pm 0.09^{\mathrm{a}}$ & $0.90 \pm 0.10^{\mathrm{a}}$ & $0.76 \pm 0.07^{\mathrm{a}}$ \\
oleic acid) & & \\
\hline & & \\
The different superscript letters within each row indicated \\
significant differences $(P<0.05)$.
\end{tabular}


regression equations showed acceptable linearity, and good recovery was obtained for spike samples and was similar to values reported in previous studies (Heshmati et al., 2017). The findings obtained during method validation were conformed with accepted criteria (AOAC International, 2002).

\section{The prevalence of AFs in sesame seeds}

In this study, 40 samples of sesame seeds were analyzed for AFs. Sesame seeds had the highest prevalence (55\%) of total AFs among the three analyzed samples. The detection rates of AFs were higher in sesame seed samples than in the tahini and tahini halva. $\mathrm{AFB}_{1}, \mathrm{AFB}_{2}, \mathrm{AFG}_{1}$, and $\mathrm{AFG}_{2}$ were detected in 19 (47.5\%), 5 (12.5\%), 6 (15\%), and $5(12.5 \%)$ of 40 sesame seeds samples, respectively (Table 4). AFB 1 was the most abundant AF, and its level varied from 0.21 to $12.35 \mu \mathrm{g} / \mathrm{kg}$. In addition, 10 and 6 samples contained $\mathrm{AFB}_{1}$ more than the accepted limit according to European $(2 \mu \mathrm{g} / \mathrm{kg})$ and Iranian standard $(5 \mu \mathrm{g} / \mathrm{kg})$, respectively, and the total AFs content of samples was lower than the permitted level in Iran $(15 \mathrm{mg} / \mathrm{kg})$.
There are several reports of AF contamination in sesame seeds (Table 5). The different levels of total AFs and $\mathrm{AFB}_{1}$ have been reported in previous similar studies. For example, Anthony et al. (2014) reported that $8(26.67 \%)$ out of 30 sesame samples studied in Nigeria were contaminated with $\mathrm{AFB}_{1}$ at levels above the limit of European regulations (Anthony et al., 2014). Esan et al. (2020) surveyed the contamination of total AFs in sesame seeds of Nigeria. They demonstrated that the positive samples contaminated with total AFs ranged from 0.29 to $88.5 \mu \mathrm{g} / \mathrm{kg}$ (Esan et al., 2020). In another study, Kollia et al. (2016) investigated 30 samples of sesame seeds from the Greek market. They observed that the amount of $\mathrm{AFB}_{1}$ in eight samples exceeded the limit of European regulations (Kollia et al., 2016). In an investigation, among 28 samples of sesame products from Egypt by Sabry et al. (2016), a higher prevalence of $\mathrm{AFB}_{1}$ and $\mathrm{AFG}_{1}$ than other mycotoxins in the range of $60 \%-100 \%$ and $33.33 \%-100 \%$, respectively, were reported. The mean range of $\mathrm{AFB}_{1}$ and $\mathrm{AFG}_{1}$ in different provinces was 18.63-66.79 and 14.88-51.47 g/kg, respectively (Sabry et al., 2016).

Table 2. Validated parameters for aflatoxin analysis in sesame and related products.

\begin{tabular}{|c|c|c|c|c|c|c|c|c|c|}
\hline \multirow{2}{*}{$\begin{array}{l}\text { Aflatoxin } \\
\text { type }\end{array}$} & \multirow[t]{2}{*}{ Equation of calibration curve } & \multirow{2}{*}{$\begin{array}{l}\text { Range of linearity } \\
(\mathrm{ng} / \mathrm{mL})\end{array}$} & \multirow[t]{2}{*}{$\mathbf{R}^{2}$} & \multicolumn{2}{|c|}{ Sesame seed } & \multicolumn{2}{|c|}{ Tahini } & \multicolumn{2}{|c|}{ Tahini halva } \\
\hline & & & & LOD & LOQ & LOD & LOQ & LOD & LOQ \\
\hline $\mathrm{AFB}_{1}$ & $Y=13562.23 X+456.03$ & $0.15-25$ & 0.998 & 0.06 & 0.21 & 0.07 & 0.23 & 0.08 & 0.27 \\
\hline $\mathrm{AFB}_{2}$ & $Y=10623.15 X-4856.45$ & $0.25-20$ & 0.997 & 0.08 & 0.25 & 0.09 & 0.31 & 0.07 & 0.22 \\
\hline $\mathrm{AFG}_{1}$ & $Y=20354.67 X+120.09$ & $0.16-20$ & 0.996 & 0.06 & 0.22 & 0.05 & 0.18 & 0.08 & 0.26 \\
\hline $\mathrm{AFG}_{2}$ & $Y=14600.18 X-809.53$ & $0.12-25$ & 0.992 & 0.04 & 0.13 & 0.06 & 0.19 & 0.07 & 0.21 \\
\hline
\end{tabular}

$L O D$ and $L O Q$ in $\mu g / k g$.

AF: aflatoxin; LOD: limit of detection; LOQ: limit of quantification.

Table 3. Recovery of aflatoxin from sesame and related products.

\begin{tabular}{lllll} 
Aflatoxin type & Spiked level $(\mu \mathrm{g} / \mathrm{kg})$ & \multicolumn{3}{c}{ Recovery \pm RSD $(\%)$} \\
\cline { 3 - 5 } & & Sesame seed & \multicolumn{1}{c}{ Tahini } & Tahini halva \\
\hline $\mathrm{AFB}_{1}$ & 0.5 & $82.15 \pm 4.51$ & $84.56 \pm 10.36$ & $87.65 \pm 12.74$ \\
& 2 & $87.63 \pm 8.56$ & $88.32 \pm 13.08$ & $90.23 \pm 15.32$ \\
$\mathrm{AFB}_{2}$ & 5 & $85.25 \pm 3.65$ & $87.32 \pm 8.98$ & $85.32 \pm 14.56$ \\
& 0.5 & $90.23 \pm 10.23$ & $79.65 \pm 4.56$ & $94.36 \pm 12.02$ \\
& 1.5 & $92.35 \pm 12.32$ & $82.36 \pm 7.25$ & $98.65 \pm 4.08$ \\
$\mathrm{AFG}$ & 3 & $95.63 \pm 15.36$ & $77.36 \pm 14.97$ & $94.82 \pm 6.23$ \\
& 0.5 & $89.69 \pm 12.31$ & $83.65 \pm 4.56$ & $88.63 \pm 4.51$ \\
& 1.5 & $92.34 \pm 8.96$ & $86.53 \pm 45.23$ & $87.56 \pm 14.23$ \\
$\mathrm{AFG}_{2}$ & 3 & $94.23 \pm 14.85$ & $82.03 \pm 12.78$ & $83.65 \pm 14.32$ \\
& 0.5 & $90.23 \pm 11.57$ & $90.23 \pm 15.63$ & $89.32 \pm 4.36$ \\
& 1.5 & $96.23 \pm 8.69$ & $95.63 \pm 10.56$ & $90.56 \pm 8.69$ \\
& 3 & $94.23 \pm 10.23$ & $92.53 \pm 8.02$ & $95.36 \pm 10.26$ \\
\hline
\end{tabular}

AF: aflatoxin; RSD: Relative standard deviation 
Table 4. The contamination status of aflatoxin of sesame and related products.

\begin{tabular}{|c|c|c|c|c|c|}
\hline Aflatoxin type & & Contamination status & Sesame seed & Tahini & Tahini halva \\
\hline \multirow[t]{6}{*}{$\mathrm{AFB}_{1}$} & Contamination level $(\mu \mathrm{g} / \mathrm{kg})$ & No. of contaminated samples & $19(47.5)$ & $14(35)$ & $11(27.5)$ \\
\hline & & Mean $\pm S D(\mu g / k g)$ & $1.67 \pm 0.45$ & $0.85 \pm 0.24$ & $0.55 \pm 0.17$ \\
\hline & & $0.15-2$ & $9(22.5)$ & $7(17.5)$ & $5(12.5)$ \\
\hline & & $2-5$ & $4(10)$ & $4(10)$ & $6(15)$ \\
\hline & & $>5$ & $6(15)$ & $3(7.5)$ & 0 \\
\hline & & Range $(\mu \mathrm{g} / \mathrm{kg})$ & $0.21-12.35$ & $0.23-5.81$ & $0.27-3.56$ \\
\hline \multirow[t]{3}{*}{$\mathrm{AFB}_{2}$} & & No. of contaminated samples & $5(12.5)$ & $3(7.5)$ & $4(7.5)$ \\
\hline & & Mean $\pm \mathrm{SD}(\mu \mathrm{g} / \mathrm{kg})$ & $0.13 \pm 0.06$ & $0.1 \pm 0.06$ & $0.07 \pm 0.03$ \\
\hline & & Range ( $\mu \mathrm{g} / \mathrm{kg})$ & $0.25-1.62$ & $0.31-1.75$ & $0.22-0.92$ \\
\hline \multirow[t]{3}{*}{$\mathrm{AFG}_{1}$} & & No. of contaminated samples & $6(15)$ & $4(10)$ & $2(5)$ \\
\hline & & Mean $\pm \mathrm{SD}(\mu \mathrm{g} / \mathrm{kg})$ & $0.10 \pm 0.05$ & $0.07 \pm 0.04$ & $0.04 \pm 0.03$ \\
\hline & & Range ( $\mu \mathrm{g} / \mathrm{kg})$ & $0.22-1.41$ & $0.18-1.32$ & $0.26-1.02$ \\
\hline \multirow[t]{3}{*}{$\mathrm{AFG}_{2}$} & & No. of contaminated samples & $5(12.5)$ & $5(12.5)$ & $4(10)$ \\
\hline & & Mean $\pm \mathrm{SD}(\mu \mathrm{g} / \mathrm{kg})$ & $0.05 \pm 0.02$ & $0.08 \pm 0.04$ & $0.06 \pm 0.03$ \\
\hline & & Range ( $\mu \mathrm{g} / \mathrm{kg})$ & $0.13-0.85$ & $0.19-1.02$ & $0.21-0.74$ \\
\hline \multirow[t]{5}{*}{ TAF } & Contamination level ( $\mu \mathrm{g} / \mathrm{kg}$ ) & No. of contaminated samples & $22(55)$ & $18(45)$ & $13(32.5)$ \\
\hline & & Mean $\pm S D(\mu g / k g)$ & $1.95 \pm 0.48$ & $1.10 \pm 0.30$ & $0.72 \pm 0.22$ \\
\hline & & $>4$ & $15(37.5)$ & $14(35)$ & $11(27.5)$ \\
\hline & & $4-15$ & $7(17.5)$ & $8(20)$ & $2(5)$ \\
\hline & & $>15$ & 0 & 0 & 0 \\
\hline
\end{tabular}

AF: aflatoxin.

\section{The prevalence of AFs in tahini}

A lower rate of AF contamination was observed in tahini than that in sesame seed. Eighteen (45\%) of Tahini samples contained total AFs. The highest prevalence of AFs in tahini halva was $\mathrm{AFB}_{1}(35 \%)$, followed by $\mathrm{AFG}_{2}(12.5 \%)$, $\mathrm{AFG}_{1}(10 \%)$, and $\mathrm{AFB}_{2}$ (7.5\%). It was observed that the $\mathrm{AFB}_{1}$ value of seven samples was higher than the limit of European regulations $(2 \mu \mathrm{g} / \mathrm{kg})$ while only three samples had $\mathrm{AFB}_{1}$ contamination higher than the recommended standard of Iran $(5 \mu \mathrm{g} / \mathrm{kg})$. Also, 18 samples contained total AF with an average value of $1.10 \pm 0.30 \mu \mathrm{g} / \mathrm{kg}$, among which the concentration of eight samples was higher than the limit of European regulations $(4 \mu \mathrm{g} / \mathrm{kg})$. It seems that washing and peeling of sesame seeds before tahini preparation could reduce the amount of AFs. Before tahini preparation, sesame seeds were roasted. The previous studies indicated that roasting operation could cause AFs degradation (Emadi et al., 2021; Yazdanpanah et al., 2005).

The prevalence of AFs in tahini was reported in other studies. For example, in a study performed by Sebaei $e t$ al.
(2020) in Egypt, mean $\mathrm{AFB}_{1}$ in 16 samples of branded tahini and 101 samples of local tahini reported $0.10 \pm$ $0.24 \mu \mathrm{g} / \mathrm{kg}$ and $13 \pm 19.3 \mu \mathrm{g} / \mathrm{kg}$, respectively (Sebaei et al., 2020). Li et al. (2009) reported that $19 \%$ and $32 \%$ of 100 of the sesame paste (Tahini) samples studied in China contained $\mathrm{AFB}_{1}$ at levels higher than the Chinese regulation $(5 \mu \mathrm{g} / \mathrm{kg})$ and European regulations (Li et al., 2009). In addition, Torlak and Akan (2013) studied AFs contamination in 104 samples of tahini from the Anatolia region of Turkey. The mean of $\mathrm{AFB}_{1}$ and total AFs of samples was $0.93 \pm 0.62 \mu \mathrm{g} / \mathrm{kg}$ and $1.17 \pm 0.55 \mu \mathrm{g}$, respectively, which both were lower than the Turkish standard $\left(\mathrm{AFB}_{1}\right.$ : $5 \mu \mathrm{g} / \mathrm{kg}$ and TAF: $10 \mu \mathrm{g} / \mathrm{kg}$ ) and our study. These authors indicated that the roasting process applied in tahini production does not eliminate AFs (Torlak and Akan, 2013).

For the traditional production of tahini, sesame is roasted for $2 \mathrm{~h}$ at a temperature of $100^{\circ} \mathrm{C}$ to $150^{\circ} \mathrm{C}$ (Torlak and Akan, 2013). AFs are resistant to heat and are difficult to eliminate at insufficient temperatures. In general, AFs are eliminated at $237^{\circ} \mathrm{C}$ to $306^{\circ} \mathrm{C}$. In foods heated, important parameters determining the reduction of $\mathrm{AF}$ include 
Table 5. The contamination status of aflatoxin of sesame and related products.

\begin{tabular}{|c|c|c|c|c|c|c|c|c|}
\hline Country & Sample type & $\begin{array}{c}\text { No of } \\
\text { samples }\end{array}$ & $\begin{array}{c}\text { Positive } \\
n(\%)\end{array}$ & Method & Mycotoxin & $\begin{array}{l}\text { Range } \\
(\mu \mathrm{g} / \mathrm{kg})\end{array}$ & $\begin{array}{c}\text { Mean } \pm \text { SD } \\
(\mu \mathrm{g} / \mathrm{kg})\end{array}$ & Reference \\
\hline Iran & Sesame seeds & 269 & $50 \%$ & HPLC & TAF & & $1.43 \pm 4.38$ & $\begin{array}{l}\text { Hosseininia et al. } \\
2014\end{array}$ \\
\hline Iran & Sesame seeds & 269 & $50 \%$ & HPLC & $\mathrm{AFB}_{1}$ & & $1.25 \pm 3.7$ & $\begin{array}{l}\text { Hosseininia et al. } \\
2014\end{array}$ \\
\hline Egyptian & Tahini (Brand) & 16 & & HPLC & $\mathrm{AFB}_{1}$ & & $0.10 \pm 0.2$ & Sebaei et al. 2020 \\
\hline Egyptian & Tahini (Local) & 101 & & HPLC & $\mathrm{AFB}_{1}$ & & $13 \pm 19.3$ & Sebaei et al. 2020 \\
\hline China & Sesame paste & 100 & $37(37 \%)$ & LC & TAF & $0.54-56.89$ & 6.75 & Li et al. 2009 \\
\hline China & Sesame paste & 100 & $37(37 \%)$ & LC & $\mathrm{AFB}_{1}$ & $0.39-20.45$ & 4.31 & Li et al. 2009 \\
\hline Iran & Sesame seeds & 182 & $33(18.1 \%)$ & LC & $\mathrm{AFB}_{1}$ & & $1.62 \pm 1.32$ & Asadi et al. 2011 \\
\hline Malaysian & Sesame seeds & 8 & $7(87.5 \%)$ & ELISA & $\mathrm{AFB}_{1}$ & $0.5-1.82$ & 0.9 & Reddy et al. 2011 \\
\hline Nigeria & Sesame seeds & 60 & 12 & LCMS/MS & TAF & $0.29-88.5$ & 16.9 & Esan et al. 2020 \\
\hline Nigeria & Sesame seeds & 60 & 12 & LCMS/MS & $\mathrm{AFB}_{1}$ & $0.29-79.3$ & 14.8 & Esan et al. 2020 \\
\hline Nigeria & Sesame seeds & 30 & 26.66 & HPLC & $\mathrm{AFB}_{1}$ & $14.71-140.90$ & $69.72 \pm 41.68$ & Anthony et al. 2014 \\
\hline Turkey & Tahini & 104 & 14.42 & HPLC & $\mathrm{AFB}_{1}$ & & $0.93 \pm 0.62$ & $\begin{array}{l}\text { Torlak and Akan } \\
2013\end{array}$ \\
\hline Turkey & Tahini & 104 & 15.38 & HPLC & TAF & & $1.17 \pm 0.55$ & $\begin{array}{l}\text { Torlak and Akan } \\
2013\end{array}$ \\
\hline Turkey & Tahini Helva & 34 & 0 & TLC & $\mathrm{AFB}_{1}$ & $<1$ & $<1$ & Var et al. 2007 \\
\hline Egyptian & Sesame seeds & 28 & 88.89 & HPLC & $\mathrm{AFB}_{1}$ & & $33.66 \pm 1.35$ & Sabry et al. 2016 \\
\hline $\begin{array}{l}\text { FCT, Abuja, } \\
\text { Nigeria }\end{array}$ & Sesame seeds & 24 & 13 & LCMS/MS & $\mathrm{AFB}_{1}$ & & 3.6 & $\begin{array}{l}\text { Fapohunda et al. } \\
2018\end{array}$ \\
\hline Nigeria & Sesame seeds & 46 & $23(50 \%)$ & TLC & $\mathrm{AFB}_{1}$ & $0.79-37.25$ & & Apeh et al. 2016 \\
\hline Japan & Sesame seeds & 47 & 5 & HPTLC & $\mathrm{AFB}_{1}$ & $0.6-2.4$ & & Tabata 2007 \\
\hline Jordan & Sesame seeds & 46 & 2 & HPLC & TAF & $100-1280$ & & Sirhan et al. 2014 \\
\hline Greek & Sesame seeds & 30 & $77.60 \%$ & HPLC & $\mathrm{AFB}_{1}$ & & $\begin{array}{c}2.0 \mathrm{ng} \text { AFB1 } \\
\mathrm{g}-1\end{array}$ & Kollia et al. 2016 \\
\hline
\end{tabular}

moisture content, heating temperature, and nutrient media. It has been reported that roasting dried wheat at $150^{\circ} \mathrm{C}$ for $30 \mathrm{~min}$, Green coffee beans at $150^{\circ} \mathrm{C}$ to $180^{\circ} \mathrm{C}$ for 10 to $15 \mathrm{~min}$, and Pistachio nuts at $150^{\circ} \mathrm{C}$ for $30 \mathrm{~min}$ will reduce AF levels to 50\%, 42.2\%-55/9\%, and 63\%, respectively (Pankaj et al., 2018).

\section{The prevalence of AFs in tahini halva}

The results showed that tahini halva samples contained four types of $\mathrm{AF}$, i.e., $\mathrm{AFB}_{1}, \mathrm{AFB}_{2}, \mathrm{AFG}_{2}$, and $\mathrm{AFG}_{2}$, with mean values of $0.55 \pm 0.17,0.07 \pm 0.03,0.04 \pm 0.03$, and $0.06 \pm 0.03 \mu \mathrm{g} / \mathrm{kg}$, respectively (Table 4). Except for $\mathrm{AFB}_{2}$, the detection rate of $\mathrm{AFB}_{1}, \mathrm{AFG}_{2}$, and $\mathrm{AFG}_{2}$ was lower in tahini halva samples than in the sesame seeds and tahini samples. The average total AFs of tahini halva samples was $0.72 \pm 0.22 \mu \mathrm{g} / \mathrm{kg}$. According to Iranian standards, the concentration of total AFs and $\mathrm{AFB}_{1}$ was not higher than the allowable limit. In contrast, the total AFs level of two samples was higher than the limit of European regulations $(4 \mu \mathrm{g} / \mathrm{kg})$. Also, in six samples, the concentration of $\mathrm{AFB}_{1}$ was higher than the limit of European regulations $(2 \mu \mathrm{g} / \mathrm{kg})$. The lower level of AFs in tahini halva could be related to the dilution effect of other products, including sugar, emulsifier, in the formulation. Few studies have been performed to evaluate AFs in tahini halva. Var et al. (2007) investigated AFB $_{1}$ contamination in 34 samples of helva in Turkey. No AFB 1 was found in helva samples. It seemed the discrepancies in AFs contamination prevalence in different studies could be due to differences in sampling geographical areas and storage conditions and the AFs measuring method.

\section{Risk assessment of AFB1 intake}

Findings of percentile 50 (as the median of the population) of EDI of $\mathrm{AFB}_{1}$ calculated using the MCS approach showed the lowest $(0.02 \mathrm{ng} / \mathrm{kg}$ bw/day) and highest (0.05 $\mathrm{ng} / \mathrm{kg}$ bw/day) of EDI in sesame seed and tahini halva, respectively (Figure 1). The percentile 95 of EDI of $\mathrm{AFB}_{1}$ through sesame seed, tahini, and tahini halva was 0.09 , 0.05 , and $0.03 \mathrm{ng} / \mathrm{kg}$ bw/day, respectively.

As shown in Figure 2, the percentile 95 of MOE with $\mathrm{AFB}_{1}$ through sesame seed, tahini, and tahini halva was calculated as 25,485, 50,092, and 77,114, respectively. Because data 
Sesame seed

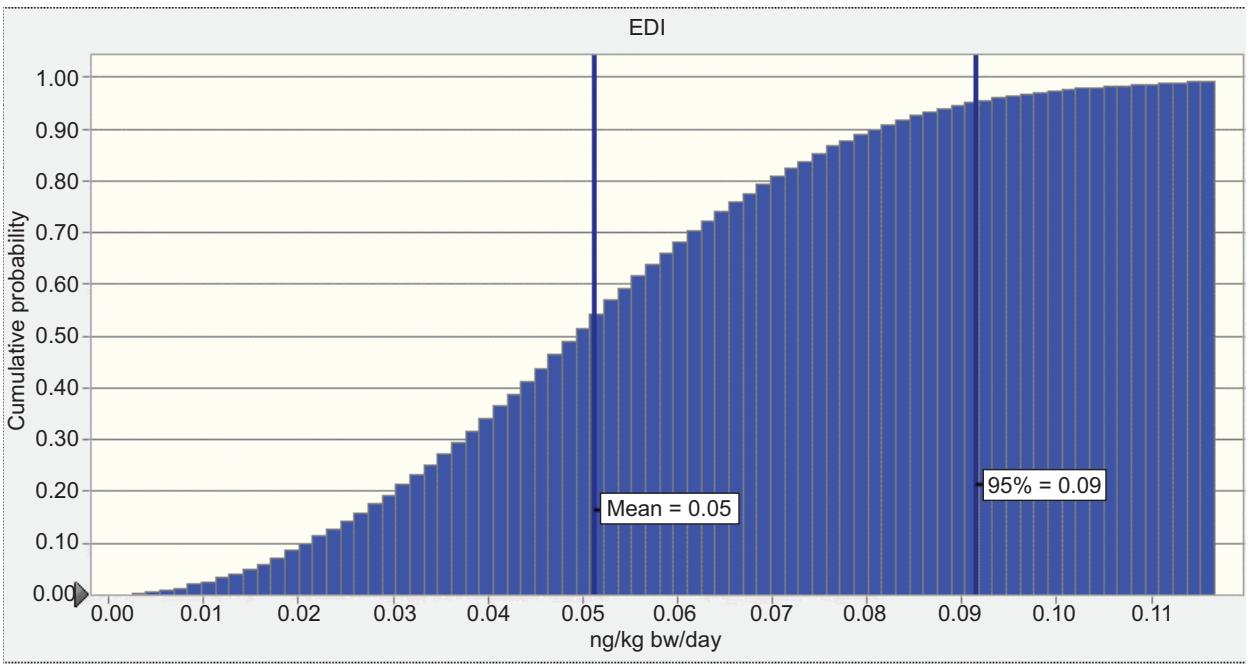

Tahini

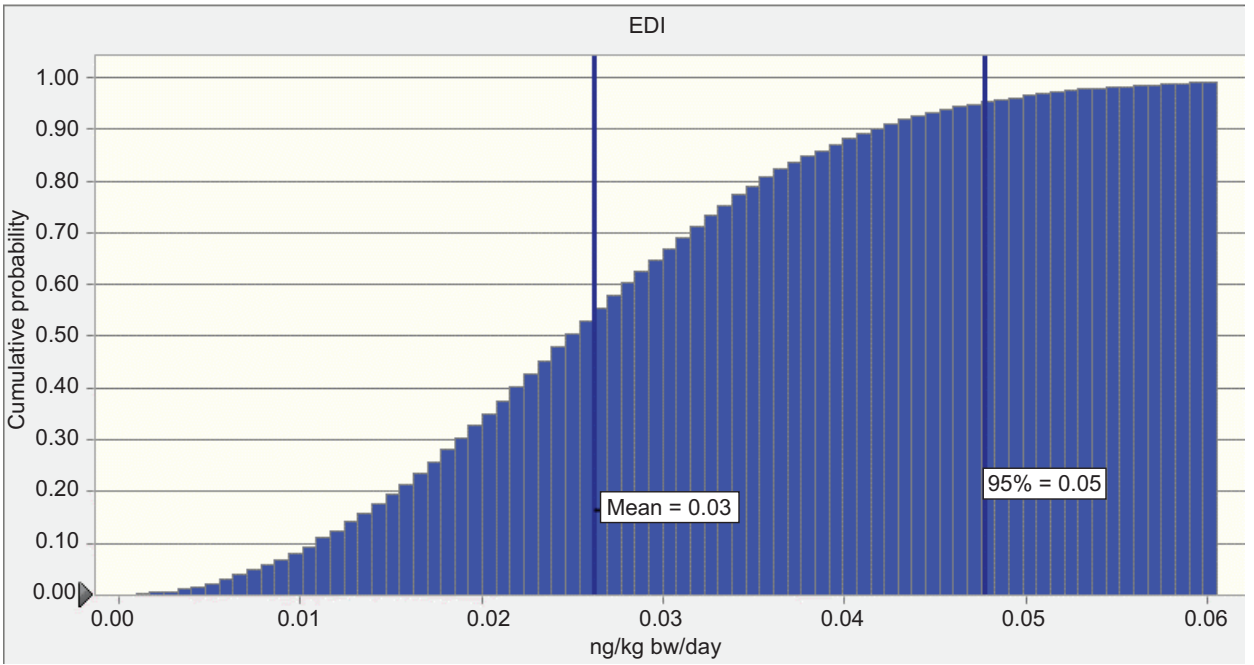

Tahini halva

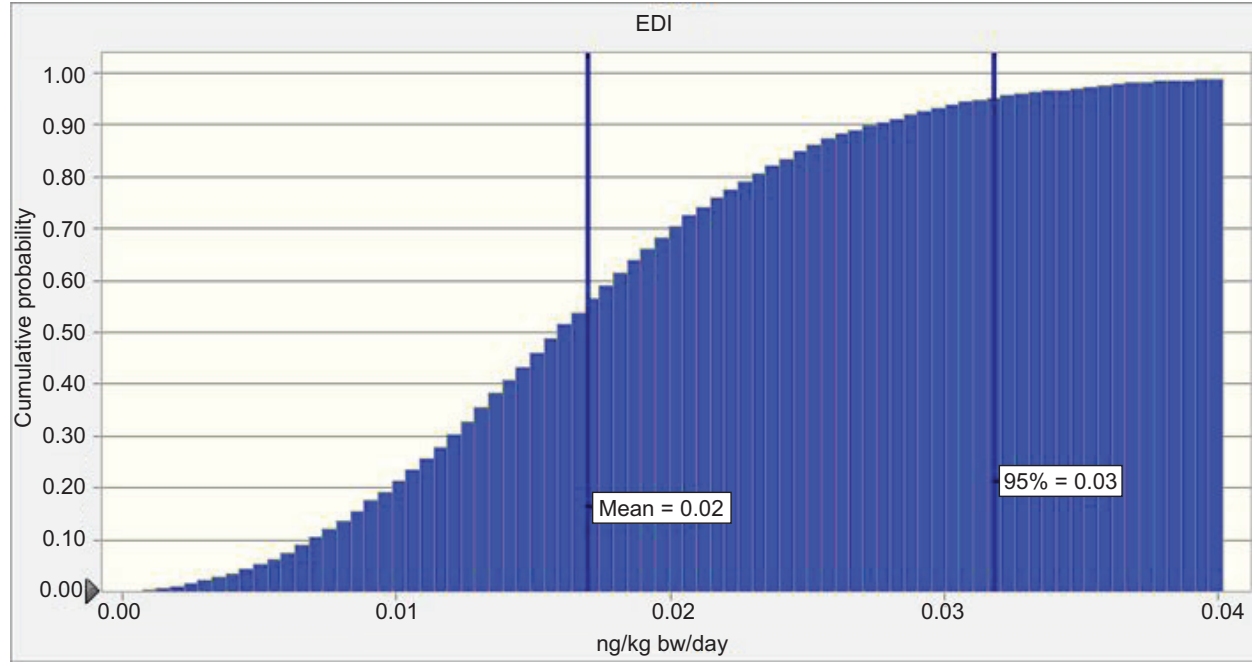

Figure 1. Cumulative probability plot of EDI of AFB1 through sesame seed, tahini, and tahini halva consumption. 
Sesame seed

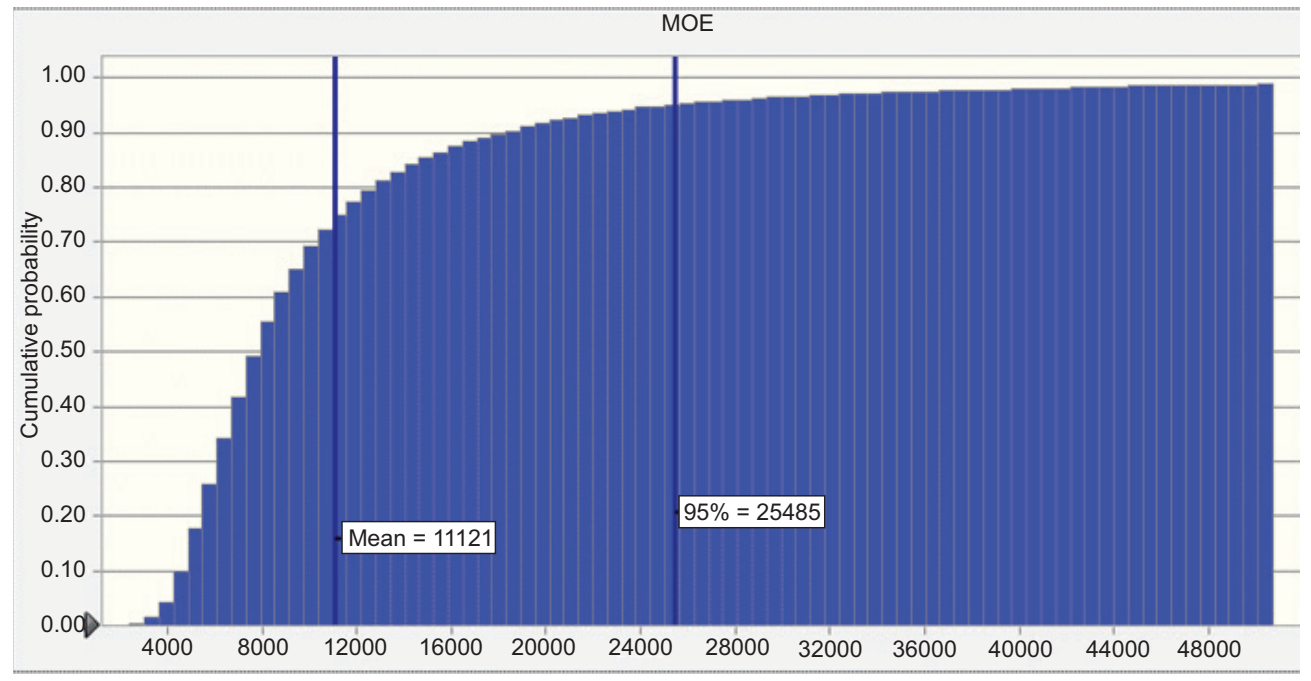

Tahini

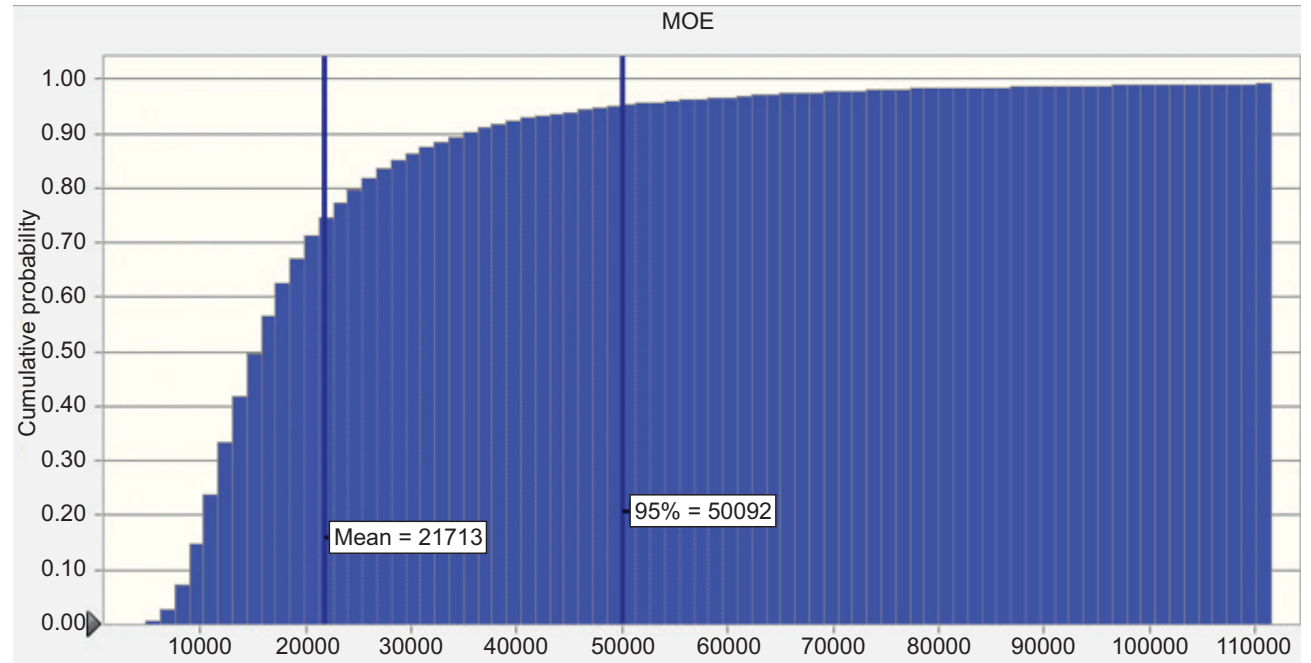

Tahini halva

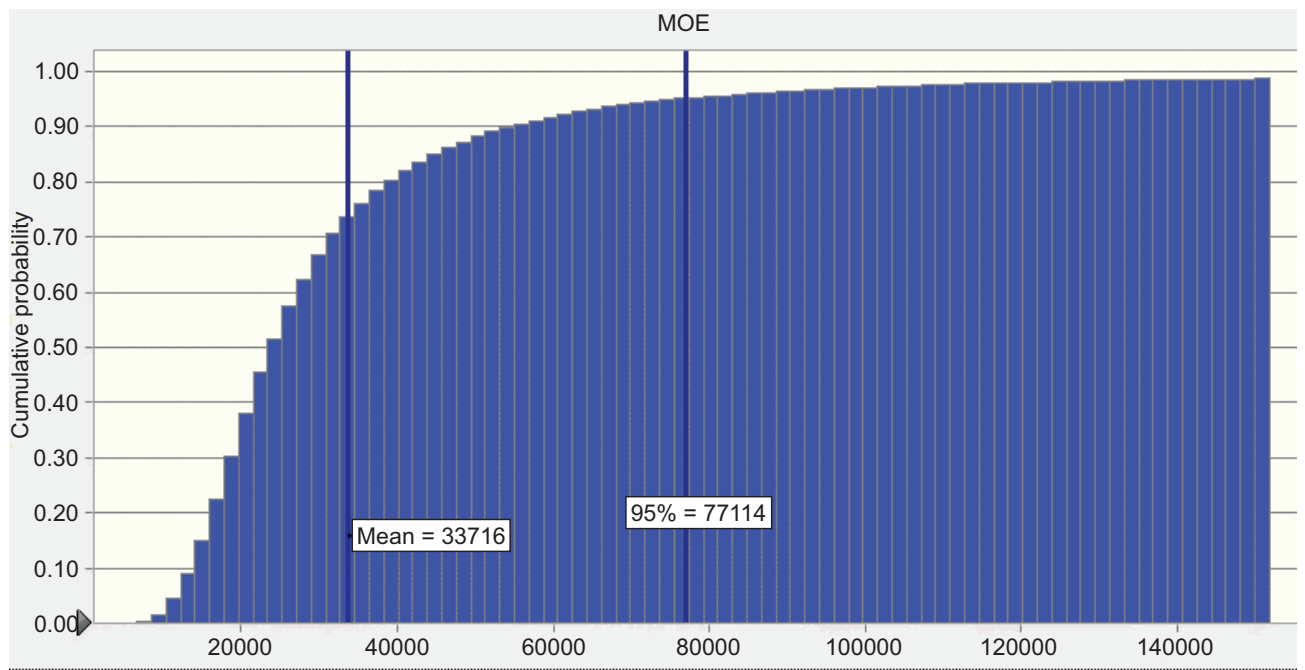

Figure 2. Cumulative probability plot of $M O E$ of $\mathrm{AFB}_{1}$ through sesame seed, tahini, and tahini halva consumption. 
regarding the percentile 50 and 95 of MOE was more than 10,000 (Heshmati et al., 2017), it could be concluded that $\mathrm{AFB}_{1}$ intake through sesame seed, tahini, and tahini halva consumption has no remarkable cancer risk for adults.

\section{Conclusions}

The results of this study indicated the high prevalence of AFs in sesame seed (55\%), tahini (45\%), and tahini halva (32.5\%) samples. In addition, the levels of TAF in 7 (17.5\%), 8 (20\%), and 2 (5\%) samples of sesame seeds, tahini, and tahini halva exceeded the limit of European regulations $(4 \mu \mathrm{g} / \mathrm{kg})$, respectively. Furthermore, 10 (25\%), 7 (17.5\%), and 6 (15\%) samples of sesame seeds, tahini, and tahini halva contained $\mathrm{AFB}_{1}$ more than the limit of European regulations $(2 \mu \mathrm{g} / \mathrm{kg})$, respectively. However, risk assessment indicated that the intake of AF through the consumption of mentioned products had no remarkable cancer risk for adults.

\section{Acknowledgments}

The ethical and scientific committee of Hamadan University of Medical Science approved this study (ethical code: IR.UMSHA.REC.1400.177).

\section{Conflict of interest}

The authors declare that they have no conflict of interest.

\section{References}

Anilakumar, K.R., Pal, A., Khanum, F. and Bawa, A.S., 2010. Nutritional, medicinal and industrial uses of sesame (Sesamum indicum L.) seeds-an overview. Agriculturae Conspectus Scientificus 75(4): 159-168.

Anthony, M.H., Ojochenemi, A.D., Yemi, A.H.R., Tahir, N., Okechukwu, O.J., Saidu, M.A., et al. 2014. Determination of aflatoxins in sesame, rice, millet and acha from Nigeria using HPLC. Chemical Science Transactions 3(4): 1516-1524. https:// doi.org/10.7598/cst2014.749

AOAC International, 2002. AOAC Guidelines for single laboratory validation of chemical methods for dietary supplements and botanicals. AOAC International, Gaithersburg, MD, USA.

Apeh, D., Ochai, D., Adejumo, A., Muhammad, H., Saidu, A., Atehnkeng, J., et al. 2016. Mycotoxicological concerns with sorghum, millet and sesame in Northern Nigeria. Analytical and Bioanalytical Chemistry 7: 336. https://doi.org/10.4172/21559872.1000336

Asadi, M., Beheshti, H.R. and Feizy, J., 2011. A survey of aflatoxins in sesame in Iran. Mycotoxin Research 27(4): 259. https://doi. org/10.1007/s12550-011-0102-y
Batrinou, A., Houhoula, D. and Papageorgiou, E., 2020. Rapid detection of mycotoxins on foods and beverages with enzyme linked immunosorbent assay. Quality Assurance and Safety of Crops \& Foods 12(1): 40-49. https://doi.org/10.15586/QAS2019.654

Chain, E.P.O.C.I.T.F., Schrenk, D., Bignami, M., Bodin, L., Chipman, J.K., Del Mazo, J., et al. 2020. Risk assessment of aflatoxins in food. EFSA Journal18(3): e06040. https://doi. org/10.2903/j.efsa.2020.604.

Cui, P., Yan, H., Granato, D., Ho, C.-T., Ye, Z., Wang, Y., et al. 2020. Quantitative analysis and dietary risk assessment of aflatoxins in Chinese post-fermented dark tea. Food and Chemical Toxicology 146: 111830. https://doi.org/10.1016/j.fct.2020.111830

De Souza, C., Khaneghah, A.M. and Oliveira, C.A.F., 2021. The occurrence of aflatoxin M1 in industrial and traditional fermented milk: a systematic review study. Italian Journal of Food Science 33(SP1): 12-23. https://doi.org/10.15586/ijfs.v33iSP1.1982

Di Sanzo, R., Carabetta, S., Campone, L., Bonavita, S., Iaria, D., Fuda, S., et al. 2018. Assessment of mycotoxins co-occurrence in Italian dried figs and in dried figs-based products. Journal of Food Safety 38(6): e12536. https://doi.org/10.1111/jfs.12536

Dravie, E.E., Kortei, N.K., Essuman, E.K., Tettey, C.O., Boakye, A.A. and Hunkpe, G., 2020. Antioxidant, phytochemical and physicochemical properties of sesame seed (Sesamum indicum L). Scientific African 8: e00349. https://doi.org/10.1016/j.sciaf.2020. e0034. 9

Eghbaljoo-Gharehgheshlaghi, H., Shariatifar, N., Arab, A., AlizadehSani, M., Sani, I.K., Asdagh, A., et al. 2020. The concentration and probabilistic health risk assessment of trace metals in three type of sesame seeds using ICP-OES in Iran. International Journal of Environmental Analytical Chemistry 1-15. https:// doi.org/10.1080/03067319.2020.1804896

Elleuch, M., Bedigian, D. and Zitoun, A., 2011. Sesame (Sesamum indicum L.) seeds in food, nutrition, and health. In: Victor R. Preedy, Ronald Ross Watson, Vinood B. Patel (Eds.), Nuts and seeds in health and disease prevention. Elsevier, Academic Press, London, pp. 1029-1036. https://doi.org/10.1016/ B978-0-12-375688-6.10122-7

Elzupir, A.O., Suliman, M.A., Ibrahim, I.A., Fadul, M.H. and Elhussein, A.M., 2010. Aflatoxins levels in vegetable oils in Khartoum State, Sudan. Mycotoxin Research. 26(2): 69-73. https://doi.org/10.1007/s12550-010-0041-z

Emadi, A., Jayedi, A., Mirmohammadkhani, M. and Abdolshahi, A., 2021. Aflatoxin reduction in nuts by roasting, irradiation and fumigation: a systematic review and meta-analysis. Critical Reviews in Food Science and Nutrition 1-11. https://doi.org/10. 1080/10408398.2021.1881436

Esan, A.O., Fapohunda, S.O., Ezekiel, C.N., Sulyok, M. and Krska, R., 2020. Distribution of fungi and their toxic metabolites in melon and sesame seeds marketed in two major producing states in Nigeria. Mycotoxin Research 36(4): 361-369. https:// doi.org/10.1007/s12550-020-00400-0

Fapohunda, S.O., Anjorin, T.S., Sulyok, M. and Krska, R., 2018. Profile of major and emerging mycotoxins in sesame and soybean grains in the Federal Capital Territory, Abuja, Nigeria European Journal of Biology Research 8(3): 121-130. https://doi. org/10.5281/zenodo.1307184 
Gholami, M., Davan, S.T., Gholami, M., Bolandparvaz, S., Gholami, M., Chamanpara, P., et al. 2020. Effects of topical sesame oil extracted from Tahini (Ardeh) on pain severity in trauma patients: A randomized double-blinded placebo-controlled clinical trial. Bulletin of Emergency and Trauma 8(3): 179. http:// dx.doi.org/10.30476/BEAT.2020.82561

Grumi, M., Kunova, A., Isotti, M., Barbiroli, A. and Pasquali, M., 2020. Occurrence of deoxynivalenol in beers commercialised in Italy. Italian Journal of Food Science 32(3): 712-720. https://doi. org/10.14674/IJFS-1826

Heshmati, A., Ghadimi, S., Ranjbar, A. and Khaneghah, A.M., 2019. Changes in aflatoxins content during processing of pekmez as a traditional product of grape. LWT 103: 178-185. https://doi. org/10.1016/j.lwt.2019.01.001

Heshmati, A., Zohrevand, T., Khaneghah, A.M., Nejad, A.S.M. and Sant'ana, A.S., 2017. Co-occurrence of aflatoxins and ochratoxin A in dried fruits in Iran: dietary exposure risk assessment. Food and Chemical Toxicology 106: 202-208. https://doi. org/10.1016/j.fct.2017.05.04.6

Hosseininia, A.R., Vahabzadeh, M., Rashedinia, M., Riahi-Zanjani, B. and Karimi, G., 2014. A survey of aflatoxins in sesame seeds imported into Khorasan Province, Iran. Mycotoxin Research 30(1): 43-46. https://doi.org/10.1007/s12550-013-0186-7

INSO, 2020. Iranian National Standardization Organization. Food and feed - maximum tolerated level of mycotoxins. No: 5925. First Revision. Iranian National Standardization Organization., Karaj, Iran.

Javanmardi, F., Khodaei, D., Sheidaei, Z., Bashiry, M., Nayebzadeh, K., Vasseghian, Y., et al. 2020. Decontamination of aflatoxins in edible oils: A comprehensive review. Food Reviews International 1-17. https://doi.org/10.1080/87559129.2020.1812635

Khaneghah, A.M., Fakhri, Y. and Sant'ana, A.S., 2018. Impact of unit operations during processing of cereal-based products on the levels of deoxynivalenol, total aflatoxin, ochratoxin A, and zearalenone: a systematic review and meta-analysis. Food Chemistry 268: 611624. https://doi.org/10.1016/j.foodchem.2018.06.072

Kollia, E., Tsourouflis, K. and Markaki, P., 2016. Aflatoxin B1 in sesame seeds and sesame products from the Greek market. Food Additives \& Contaminants Part B 9(3): 217-222. https://doi.org/ 10.1080/19393210.2016.1179349

Lee, B.M., Lee, E.M., Kang, D.J., Seo, J.-A., Choi, H.-K., Kim, Y.-S., et al. 2020. Discovery study of integrative metabolic profiles of sesame seeds cultivated in different countries. LWT 129: 109454. https://doi.org/10.1016/j.lwt.2020.109454.

Li, F.-Q., Li, Y.-W., Wang, Y.-R. and Luo, X.-Y., 2009. Natural occurrence of aflatoxins in Chinese peanut butter and sesame paste. Journal of Agricultural and Food Chemistry 57(9): 3519-3524. https://doi.org/10.1021/jf804055n

Milicevic, B., Tomović, V., Danilović, B. and Savić, D., 2021. The influence of starter cultures on the lactic acid bacteria microbiota of Petrovac sausage. Italian Journal of Food Science 33(2): 24-34. https://doi.org/10.15586/ijfs.v33i2.1918

Mokhtarian, M., Tavakolipour, H., Bagheri, F., Oliveira, C.A.F., Corassin, C.H. and Khaneghah, A.M., 2020. Aflatoxin B1 in the Iranian pistachio nut and decontamination methods: a systematic review. Quality Assurance and Safety of Crops \& Foods 12(4): 15-25. https://doi.org/10.15586/qas.v12i4.784.

Mozaffari Nejad, A.S., Heshmati, A. and Ghiasvand, T., 2020. The occurrence and risk assessment of aflatoxin M1 in cheeses samples from Hamadan, Iran. Iranian Journal of Pharmaceutical Research 19(4): 44-50. https://doi.org/10.22037/ijpr.2020. 112399.13754

Namiki, M., 2007. Nutraceutical functions of sesame: a review. Critical Reviews in Food Science and Nutrition 47(7): 651-673. https://doi.org/10.1080/10408390600919114

Öğütcü, M., Arifoğlu, N. and Yllmaz, E., 2017. Restriction of oil migration in tahini halva via organogelation. European Journal of Lipid Science and Technology 119(9): 1600189. https://doi. org/10.1002/ejlt.201600189

Osaili, T.M., Al-Nabulsi, A.A. and Aljaafreh, T.F., 2018a. Use of gamma radiation for inactivating Salmonella spp., Escherichia coli O157: H7 and Listeria monocytogenes in tahini halva. International Journal of Food Microbiology 278: 20-25. https:// doi.org/10.1016/j.ijfoodmicro.2018.04.029

Osaili, T.M., Al-Nabulsi, A.A., Aljaafreh, T.F. and Olaimat, A.N., 2018b. Use of gamma radiation to inactivate stressed Salmonella spp., Escherichia coli O157: H7 and Listeria monocytogenes in tahini halva. LWT 98: 438-443. https://doi.org/10.1016/j. lwt.2018.09.017

Pankaj, S., Shi, H. and Keener, K.M., 2018. A review of novel physical and chemical decontamination technologies for aflatoxin in food. Trends in Food Science \& Technology 71: 73-83. https:// doi.org/10.1016/j.tifs.2017.11.007

Rapa, M., Ciano, S., Gobbi, L., Ruggieri, R. and Vinci, G., 2021. Quality and safety evaluation of new tomato cultivars. Italian Journal of Food Science 33(2): 35-45. https://doi.org/10.15586/ ijfs.v33i2.1921

Reddy, K.R., Farhana, N.I. and Salleh, B., 2011. Occurrence of Aspergillus spp. and aflatoxin B1 in Malaysian foods used for human consumption. Journal of Food Science 76(4): T99-T104. https://doi.org/10.1111/j.1750-3841.2011.02133

Sabry, B.A., Hathout, A.S., Nooh, A., Aly, S.E. and Shehata, M.G., 2016. The prevalence of aflatoxin and Aspergillus parasiticus in Egyptian sesame seeds. International Journal of Chemtech Research 9(11): 308-319.

Sebaei, A.S., Refai, H.M., Elbadry, H.T. and Armeya, S.M., 2020. First risk assessment report of aflatoxins in Egyptian tahini. Journal of Food Composition and Analysis 92: 103550. https:// doi.org/10.1016/j.jfca.2020.103550

Sirhan, A.Y., Tan, G.H., Al-Shunnaq, A., Abdulra'uf, L. and Wong, R.C., 2014. QuEChERS-HPLC method for aflatoxin detection of domestic and imported food in Jordan. Journal of Liquid Chromatography \& Related Technologies 37(3): 321342. https://doi.org/10.1080/10826076.2012.745138

Tabata, S., 2007. Mycotoxin contamination in foods and foodstuffs in Japan Aflatoxins. JSM Mycotoxins 2006(Suppl 4): 123-129. https://doi.org/10.2520/myco1975.2006.Suppl4_123

Torlak, E. and Akan, I., 2013. Aflatoxin contamination in tahini. Quality Assurance and Safety of Crops \& Foods 5(3): 221-225. https://doi.org/10.3920/QAS2012.0131 
Var, I., Kabak, B. and Gök, F., 2007. Survey of aflatoxin B1 in helva, a traditional Turkish food, by TLC. Food Control 18(1): 59-62. https://doi.org/10.1016/j.foodcont.2005.08.008

Wang, Y.-J., Nie, J.-Y., Zhen, Y., Li, Z.-X., Cheng, Y. and Farooq, S., 2018. Multi-mycotoxin exposure and risk assessments for Chinese consumption of nuts and dried fruits. Journal of Integrative Agriculture 17(7): 1676-1690. https://doi. org/10.1016/S2095-3119(18)61966-5

Xinyu, Z., Yi, W., Xue, H., Zixi, Y., Weiqiong, Y. and Zhaolin, L., 2020. Characterization of volatile compounds in five blueberry varieties using purge and trap coupled to gas chromatography-mass spectrometry. Italian Journal of Food Science 32(2): 482-497. https://doi.org/10.14674/IJFS-1675

Yao, Y.-G., Wang, W.-Y., Chen, L.-Y., Liu, H.-M., Yan, R.-Z., Li, S., et al. 2021. Structural changes of cellulosic polysaccharides in sesame hull during roasting at various temperatures. Quality Assurance and Safety of Crops \& Foods 13(2): 13-24. https:// doi.org/10.15586/qas.v13i2.876

Yazdanpanah, H., Mohammadi, T., Abouhossain, G. and Cheraghali, A.M., 2005. Effect of roasting on degradation of aflatoxins in contaminated pistachio nuts. Food and Chemical Toxicology 43(7): 1135-1139. https://doi.org/10.1016/j.fct. 2005.03.004

Zebib, H., Bultosa, G. and Abera, S., 2015. Physico-chemical properties of sesame (Sesamum indicum L.) varieties grown in Northern Area, Ethiopia. Agricuture Science 6(02): 238-246. https://doi.org/10.4236/as.2015.62024. 